\title{
Correction to "Fertility Awareness-Based Methods: Another Option for Family Planning"
}

In the above-mentioned article, ${ }^{1}$ under the Basal Body Temperature heading, the conversion from Fahrenheit to Celsius was incorrect. The sentence in question should read, "The luteinizing hormone surge, which stimulates ovulation, is associated with a $0.5-$ to $1^{\circ} \mathrm{F}-\left(0.3\right.$ to $\left.0.6^{\circ} \mathrm{C}-\right)$ rise in BBT measured with highly standardized methods." The electronic version on the Journal of the American Board of Family Medicine website has been corrected. We apologize for the error, and we regret any confusion or inconvenience it may have caused.

doi: $10.3122 / \mathrm{jabfm} .2013 .04 .130168$

\section{Reference}

1. Pallone SR, Bergus GR. Fertility awareness-based methods: another option for family planning. J Am Board Fam Med 2009;22:147-57.

\section{Correction to "Content Usage and the Most Frequently Read Articles by Issue in 2012"}

In the above-mentioned article, ${ }^{1}$ an incorrect URL was listed in Table 1. The link to the article, Current Oral Antiplatelets: Focus Update on Prasugrel, ${ }^{2}$ should be: http://jabfm.org/content/25/3/343.full. The electronic version on the Journal of the American Board of Family Medicine website has been corrected. We apologize for the error, and we regret any confusion or inconvenience it may have caused.

\section{doi: 10.3122/jabfm.2013.04.130174}

\section{References}

1. Lupo P, Neale AV, Bowman MA. Content Usage and the Most Frequently Read Articles by Issue in 2012. J Am Board Fam Med 2013;26:229-31.

2. John J, Koshy SKG. Current oral antiplatelets: focus update on prasugrel. J Am Board Fam Med 2012;25:343-9. 